\title{
ESCALONAMENTO DE TECNOLOGIAS: DESENVOLVIMENTO DE PRODUTO E PROCESSO DO LABORATÓRIO À ESCALA PILOTO CONECTADO AO MERCADO (PARTE 1)
}

\author{
Elimar Pires Vasconcellos ${ }^{\mathrm{a}}$, Priscila Maria Teixeira Gonçalves de Souzab ${ }^{\mathrm{b}}$, Marcella Rocha Franco ${ }^{\mathrm{b}}$, Vinícius Gomide de \\ Castro $^{\mathrm{b}}$, Lorena Viana Souza ${ }^{\mathrm{b}}$, Rochel Montero Lago ${ }^{\mathrm{c}}$ e Marcelo Gomes Spezialid,*,i] \\ aAssociação Wylinka: Inovação, Ciência, Tecnologia e Negócios, 30130-174 Belo Horizonte - MG, Brasil \\ 'Fundação de Desenvolvimento e Pesquisa - Unidade Administrativa II, 31270-901 Belo Horizonte - MG, Brasil \\ 'Departamento de Química, Instituto de Ciências Exatas, Universidade Federal de Minas Gerais, 31270-901 Belo Horizonte - MG, \\ Brasil \\ ¿Departamento de Química, Instituto de Ciências Exatas e Biológicas, Universidade Federal de Ouro Preto, Campus Universitário \\ Morro do Cruzeiro, 35400-000 Ouro Preto - MG, Brasil
}

Recebido em 04/08/2020; aceito em 05/10/2020; publicado na web em 04/11/2020

\begin{abstract}
TECHNOLOGY SCALE UP: PROCESS DEVELOPMENT FROM THE LABORATORY TO PILOT SCALE CONNECTED TO MARKET (PART 1). In this article, it is described the main aspects to be considered during the process of scaling up hard sciences technologies developed in the Science and Technology Institutes aiming at industrial application. Based on the experience of our group in scaling up, pre-acceleration, and acceleration of different technologies, a methodology was developed and divided into four main stages: Step 1, which involves basic research, Step 2 with a focus on product development, and Step 3 with a focus on process development, all on the laboratory scale and the last one, Step 4 focused on pilot plant development. The most important aspect of this article is to show that many critical questions can be answered even in the laboratory phase. In this way, the risks of Step 4 are minimized. Step 4 is a complicated, lengthy, and expensive process of construction and operation of a pilot plant. Aspects such as proof of concept, technical and economic feasibility studies, minimum viable product, capital expenditures, and operating expenses of pilot plants are approached in a simplified way to serve as a basis for researchers who wants to know the long path to be followed by technology before reaching the industry, consequently the market.
\end{abstract}

Keywords: scaling up; pilot plant; proof of concept.

\section{INTRODUÇÃO}

O conceito de Boer H. e During W. E. ${ }^{1}$ define que inovação é a exploração de novas ideias com sucesso. Essas ideias podem estar relacionadas com o desenvolvimento de novos produtos, processos e serviços, bem como novas formas de aplicação ou novos modelos de negócios. Dessa forma, uma ideia só se torna uma inovação efetiva quando é, de fato, introduzida no mercado ou na sociedade com sucesso.

Instituições de Ciência e Tecnologia (ICTs) têm um papel fundamental para a inovação, pois são as principais responsáveis por realizar pesquisas e gerar o conhecimento utilizado como base para o desenvolvimento de novas tecnologias. ${ }^{2}$ No entanto, esse conhecimento tem ficado guardado em nossas universidades em monografias, teses e artigos. Como levar esse conhecimento para a indústria e o mercado fazendo que a ciência e as ICTs tenham um impacto muito maior na sociedade?

Tecnologias encontradas em grupos de pesquisa ligados às universidades, comumente, mostram baixa maturidade tecnológica e precisam ainda percorrer um longo caminho até se transformarem em inovações completamente implementáveis. No caso da química e de algumas outras áreas chamadas Hard Sciences (engenharias, física, biologia, etc.) uma das grandes dificuldades no processo de inovação é o escalonamento da tecnologia, i.e. sair da escala de miligramas ou gramas, que são feitos em laboratório de pesquisa, para a escala de quilos ou centenas de quilogramas. ${ }^{3,4}$ Esse processo de escalonamento é fundamental para se levar um produto dos laboratórios de pesquisa para o mercado, pois através dele se obtém informações necessárias

*e-mail: speziali@ufop.edu.br sobre a viabilidade técnica, econômica e mercadológica do novo produto.

O escalonamento é um conceito amplo e com diferentes denominações, tais como aumento de escala ou "scale up", sendo na engenharia química descrito como a reprodução dos resultados técnicos obtidos em menores escalas (laboratoriais), por meio de operações químicas e/ou físicas para maiores escalas com o objetivo de se obter um novo produto comercial. ${ }^{5}$ Outros autores abordam o escalonamento como um processo utilizado na expansão, replicação e adaptação de resultados de sucesso em uma escala industrial, com base em experimentações anteriores, que deve ser enquadrado no ciclo inovação-aprendizagem-expansão. ${ }^{6}$ Linn e Cooley ${ }^{6}$ afirmam que apenas o conhecimento teórico não é suficiente para o sucesso no escalonamento, fazendo-se necessário o conhecimento prático baseado em experimentações específicas. Tal conhecimento é visto como tácito, que significa o conhecimento pessoal e individual, e compreende elementos técnicos e cognitivos de difícil tradução e comunicação. Além do conhecimento tácito, a multidisciplinaridade e o envolvimento de profissionais com diferentes formações são importantes. ${ }^{5}$ Portanto, torna-se essencial a interação entre cientistas com elevados conhecimentos teóricos, engenheiros com conhecimento e vivência prática e pessoas da área de negócios para se alcançar sucesso no escalonamento.

Nesse contexto e com o recorte nos desenvolvimentos tecnológicos dentro das Hard Sciences, a pergunta central que se busca responder neste artigo é: "Como levar uma pesquisa em estágio de laboratório para a escala industrial e para o mercado?". Trata-se de um caminho de alta complexidade e sem metodologia única, mas que envolve aspectos importantes que devem ser levados em consideração durante todo o processo da bancada ao mercado. 
Vale enfatizar que essa metodologia foi desenvolvida com base em várias experiências em escalonamento realizados na empresa de base tecnológica Verti Ecotecnologias e no Laboratório de Escalonamento do INCT Midas (ESCALAB, www.escalab.com.br), em programas de pré-aceleração (Laboratório de Negócios Midas, Programa Hands on, SBQ Acelera, Biostartup Lab, Programa Lemonade) e de aceleração (ESCALE-SE, FIEMGLab e Rebelbio) que os autores executaram e participaram. A sequência de etapas de desenvolvimento de uma tecnologia e aspectos relevantes de sua evolução dependem diretamente da aplicação customizada dos conceitos relatados no estado da arte, como as 5 forças de Porter, ${ }^{7,8}$ o mínimo produto viável (MVP), a prova de conceito (POC) e o estudo de viabilidade técnica e econômica e impacto ambiental e Social (EVTECIAS). Portanto, questões fundamentais que auxiliem no amadurecimento de uma tecnológica, consequentemente seu escalonamento, combinam um conhecimento tácito com um importante referencial teórico para fornecer uma metodologia de referência útil para os desafios envolvidos neste campo.

A Figura 1 mostra de forma simplificada as 4 etapas de escalonamento de tecnologias em estágio de laboratório que serão abordadas de forma mais aprofundada quanto ao seu objetivo, a escala, os aspectos críticos, as provas de conceito (POC) e as principais perguntas a serem respondidas em cada estágio.

\section{ETAPAS DO ESCALONAMENTO}

Etapa 1: desenvolvimento de pesquisa de laboratório já conectada à aplicação

Objetivo da Etapa 1: obter em laboratório um potencial produto de forma reprodutível e com boa compreensão da química do sistema.

Escala da Etapa 1: miligramas/gramas/mililitros.

Essa primeira etapa envolve a pesquisa básica de laboratório. Segundo Shane, ${ }^{9}$ essa é uma etapa iniciada naturalmente por uma pesquisa acadêmica, na qual os esforços iniciais são dedicados a uma profunda revisão do estado da técnica e da arte, objetivando definir conceitos iniciais, como características básicas e algumas das potenciais aplicações da tecnologia. Nessa fase, o objetivo normalmente é definir ou ampliar as bases científicas para o entendimento de fenômenos motivados pela curiosidade intelectual e o avanço da ciência.

Pesquisadores que desejam desenvolver e levar tecnologias até à sociedade tem como desafio dessa etapa realizar uma pesquisa altamente aplicada, mas que ao mesmo tempo tenha relevância acadêmica com base em uma ciência de ponta. Nesse contexto, é importante perceber que a pesquisa aplicada e a pesquisa básica não são conflitantes, mas sim complementares. Um segundo aspecto, que é desejável de ser considerado nessa fase, é a realização da pesquisa conectada a aspectos de mercado e potenciais clientes desde o início. Para isso, sugere-se a realização de uma Prova de Conceito inicial denominada de POC 1 para validar se a tecnologia funciona em condições de laboratório.

\section{Prova de Conceito 1 (POC 1) - Validação inicial da tecnologia}

Objetivos da POC 1: A POC 1 realizada ainda em escala de laboratório permite demonstrar que a tecnologia/produto funcionam, bem como, mensurar de forma preliminar sua eficiência quando comparada a outras tecnologias/produtos existentes no mercado. No entanto, é importante ressaltar que depois da realização de uma POC em laboratório ainda não há uma tecnologia/produto efetivo, mas uma validação da funcionalidade da tecnologia/produto. Vale enfatizar, que uma vez definida e validada a aplicação da tecnologia é importante começar a pensar na estratégia de proteção intelectual e iniciar o mapeamento das tecnologias subjacentes, com base no estado da técnica. ${ }^{10} \mathrm{~A}$ avaliação dessa etapa pode ser beneficiada pelo estudo das 5 forças de Porter, ${ }^{7,8}$ que consideram a rivalidade entre concorrentes como ponto central, ameaça de produtos substitutos, ameaça de novos entrantes, poder de barganha dos clientes e poder de barganha dos fornecedores. Entender os concorrentes e produtos substitutos é fundamental para a compreensão do mercado, pois é praticamente impossível que a tecnologia em desenvolvimento não possua nenhum concorrente, mesmo que através de produtos de diferentes características com algum campo de aplicação em comum. A ameaça de novos entrantes também é de extrema importância para entender se o produto pode ser facilmente reproduzível ou se há barreiras significativas de entrada para concorrentes, o que representa uma maior segurança de acesso prolongado a um nicho de mercado. A avaliação da existência de múltiplos fornecedores ou de insumos com maior concentração de fornecimento é relevante para avaliação do poder de barganha das empresas representantes e uma possível indicação de insumos mais atrativos para o estudo. O poder de barganha também é um fator pertinente, o que é minimizado pela razão de muitos clientes para poucos fornecedores. Dentro desse contexto, o entendimento do grau de diferenciação visado para o produto e seus benefícios de aplicação é um ponto essencial para o mapeamento das vantagens competitivas existentes nesses diversos atributos. Assim, o estudo das 5 forças de Porter contribui para a avaliação de posicionamento do produto visado, que por sua vez pode auxiliar no direcionamento da tecnologia em desenvolvimento, portanto, é fundamental começar essas reflexões desde o momento inicial do escalonamento.

\section{Estudo de viabilidade técnica e econômica e impacto ambiental e social (EVTECIAS)}

O Estudo de Viabilidade Técnica e Econômica e Impacto Ambiental e Social, conhecido como EVTECIAS tem o objetivo de verificar as possibilidades de sucesso ou fracasso de um negócio ou produto. Ele deve ser construído levando em consideração aspectos técnicos, comerciais, operacionais, econômicos, ambientais e algumas vezes sociais. É importante que na Etapa 1 de escalonamento seja feito
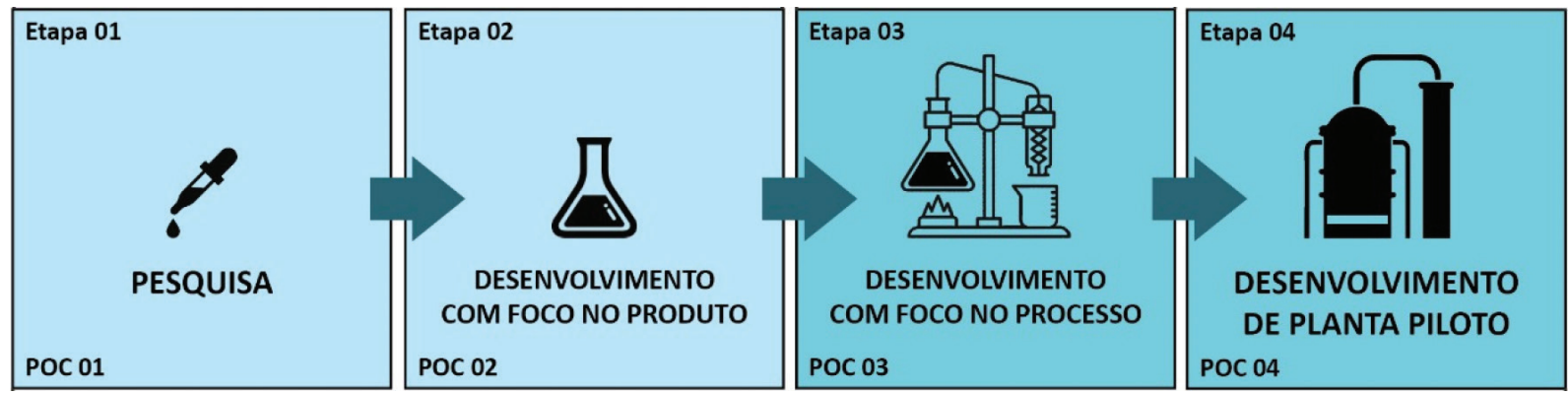

Figura 1. As quatro etapas fundamentais do processo de escalonamento de tecnologias 
um EVTECIAS de forma simplificada, para que as primeiras direções das etapas futuras de escalonamento comecem a ir aparecendo para a equipe de pesquisa. À medida que o projeto vai evoluindo é importante que o detalhamento do EVTECIAS também evolua de forma dinâmica, com isso a tecnologia irá ganhando mais maturidade. Por exemplo, se o preparo do produto necessita de um insumo extremamente complexo que não está disponível no mercado, ou um equipamento especial sofisticado, isso pode inviabilizar tecnicamente ou economicamente o processo e, portanto, sua rota de preparo deve ser repensada. Outro fator importante é verificar a viabilidade econômica do produto a ser desenvolvido, sendo essencial mensurar os custos relacionados à fabricação do mesmo e compará-los com o valor de outros produtos existentes no mercado.

Para avançar para a etapa seguinte de escalonamento é importante que a equipe técnica faça uma reflexão sobre o real estágio de amadurecimento da tecnologia e verifique as condições para avançar no escalonamento ou ajustar parâmetros básicos da pesquisa de bancada (Quadro 1). As respostas a esses questionamentos deverão ser muito bem avaliadas para passar para a próxima etapa. É importante frisar que dentro dos quadros de perguntas (Quadro 1, 3, 5 e 7), apresentados abaixo, não existe uma ordem cronológica de avaliação das perguntas. A recomendação é que todas as perguntas sejam respondidas em bloco antes de se passar para o próximo estágio. $\mathrm{O}$ fato de uma ou outra pergunta não ter sido respondida não inviabilizará que $\mathrm{o}(\mathrm{s})$ pesquisador(es) avance $(\mathrm{m})$ para a próxima etapa, entretanto, nesse caso, os riscos aumentarão significativamente. No caso de nenhuma pergunta poder ser respondida, a inviabilidade do projeto em questão será certeira. Nesse caso, é recomendado que $\mathrm{o}(\mathrm{s})$ pesquisador(es) retroceda $(\mathrm{m})$ pelo menos uma etapa e faça $(\mathrm{m})$ novamente reavaliação de toda etapa anterior.

Quadro 1. Perguntas fundamentais a serem respondidas na Etapa 1

1. Foi realizada uma busca de patentes e artigos? O produto/processo já é patenteado? É importante fazer uma verificação e uma análise das tecnologias presentes no estado da técnica, visto que, tais observações podem contribuir diretamente na construção de requisitos de aplicação industrial, na estratégia adotada de proteção intelectual e na identificação de potenciais parceiros, bem como, concorrentes.

2. Baseado nos trabalhos de laboratório, o processo funciona bem? É reprodutível? O produto atende as expectativas mínimas?

3. Foi realizada uma análise preliminar EVTECIAS que não mostrou qualquer grande limitação?

4. O seu processo ou produto está sujeito a alguma regulamentação que pode influenciar, facilitar e/ou inviabilizar o desenvolvimento e aplicação?

5. O seu processo ou produto depende de algum insumo que não existe, difícil de encontrar, extremamente caro, ou depende de algum processo muito especial de produção? Essa dependência poderia inviabilizar o produto ou processo?

6. O desenvolvimento da tecnologia ainda continua atrativo?

De forma a ilustrar a Etapa 1, descrevemos abaixo (c.f. Quadro 2) um estudo de caso de uma POC feita com argila hidrofobizada para absorver óleo em acidentes de derramamento.

\section{Etapa 2: desenvolvimento com foco no produto ainda em laboratório}

Objetivo: preparar quantidades maiores em relação à Etapa 1, substituindo reagentes de laboratório de alta pureza por insumos comerciais e testar as funcionalidades do "produto" de forma mais robusta.
Quadro 2. Caso de estudo - Argilas hidrofóbicas

Foi desenvolvido em laboratório uma argila hidrofóbica, baseada em vermiculita, para a captura de óleo derramado em acidentes ocorridos no mar (nesse momento, já havia sido feito uma busca na literatura procurando artigos e patentes semelhantes). Para demonstrar que a tecnologia funcionava utilizou-se vários tipos de óleos, como óleo diesel, gasolina, óleo vegetal e petróleo (tentativa de responder à pergunta 1). Os experimentos foram conduzidos em escala de laboratório, com o auxílio de um béquer de $500 \mathrm{~mL}$ contendo água e óleo em sua superfície. Adicionou-se ao meio a argila e foi medido o quanto de óleo essa conseguia remover. Além disso, diversos materiais comerciais foram testados de forma comparativa (iniciou-se a construção de um EVTECIAS preliminar). Dessa forma, com esses experimentos pôde-se demonstrar que a tecnologia funcionava, além de medir de forma preliminar a eficiência dos materiais, quando comparados a outros produtos existentes no mercado (tentativa de responder à pergunta 5). Em paralelo ao trabalho de laboratório, a mesma equipe responsável pelo trabalho de bancada havia começado a buscar informações sobre órgãos reguladores e eventuais limitações administrativas que pudessem ser algum complicador futuro. Após essa primeira longa jornada o projeto ainda se mostrava bastante atrativo.

Escala: aproximadamente gramas até $1 \mathrm{~kg}$.

Deve-se iniciar a execução de experimentos com a utilização de insumos disponíveis comercialmente/industrialmente, para aproximar à realidade de escala piloto e avaliar seu impacto na eficiência do processo e na qualidade do produto. Além de testes laboratoriais, também seria muito interessante se as funcionalidades do produto pudessem ser validadas com potenciais clientes nessa fase, uma vez que esses clientes poderão ser os principais interessados no desenvolvimento da tecnologia.

Para a execução dessa fase, faz-se necessária uma infraestrutura de laboratório de pesquisa com vidrarias e equipamentos que comportem quantidades maiores de insumo, ao se comparar com a fase anterior. Como exemplo, ao se considerar um laboratório de química, deve-se utilizar recipientes com volumes na faixa de litros, balanças de maior capacidade de pesagem que às analíticas, etc. A ideia é aumentar a escala para dezenas de gramas ou até quilogramas, de modo a conseguir reproduzir as mesmas funcionalidades obtidas na fase anterior para o produto em desenvolvimento. Nesse contexto, torna-se clara a importância de verificar se os resultados são reprodutíveis e encontram-se dentro das faixas de qualidade já estabelecidas. Normas, como as publicadas pela ABNT devem começar a ser avaliadas para um possível enquadramento do produto/processo.

O início do estudo da utilização de reagentes comerciais é fundamental, a fim de garantir a adequação às condições futuras de operação industrial e a viabilidade econômica do processo. $\mathrm{O}$ uso de reagentes de laboratório é justificado apenas para um conjunto de processos de alta sensibilidade, que envolvam o consumo reduzido de insumos e produtos de alto valor agregado (como em química fina). No entanto, dificilmente há viabilidade econômica para a aplicação de tais matérias-primas no contexto de produção industrial. Nessa etapa, o uso de insumos industriais pode demandar alguns ajustes (concentração dos reagentes, intensidade da agitação, temperatura, etc.) para manter as características finais do produto.

Outro ponto importante ainda nessa fase é a realização de testes do produto com relação ao seu desempenho, de preferência com potenciais clientes, uma vez que novamente esses poderão ser um dos principais interessados no desenvolvimento da tecnologia. A continuidade do aumento de escala dependerá da validação de que o produto pode de fato gerar os benefícios e funcionalidades de interesse do mercado. Assim, um fator crucial que aumenta as chances de sucesso do desenvolvimento do produto nesta fase é o conhecimento e aproximação dos pesquisadores junto ao mercado. 
Também, a comparação do desempenho do produto com outros produtos já disponíveis comercialmente, possibilita a obtenção de informações de extrema relevância a respeito das funcionalidades essenciais para o desenvolvimento do produto e/ou processo com elevada qualidade. Conhecer o mercado permite que os pesquisadores compreendam sua "dor", ou seja, reconhecer, bem como definir, qual o problema de fato poderá ser resolvido com a aplicação de sua tecnologia desenvolvida. ${ }^{11}$

\section{Prova de Conceito 2 - Validação do produto}

Objetivos da POC 2: entender melhor o produto e avaliar seu desempenho, ou seja, suas funcionalidades em ambiente efetivo.

$\mathrm{Na}$ POC 2, espera-se realizar um teste do produto mais detalhado e robusto, diferente dos estudos mais acadêmicos e fundamentais. Conforme descrito anteriormente, a conexão com parceiros iniciada nessa fase é de extrema importância para testar o produto, pois quando realizado junto a um usuário real (cliente), pode tornar a prova de conceito mais assertiva. Nesse sentido, a prova de conceito pode ser denominada de MVP (mínimo produto viável, do inglês minimum viable product). ${ }^{12,13} \mathrm{O}$ MVP pode ser descrito como um produto desenvolvido com o mínimo de recursos possíveis, com o objetivo de realizar testes de sua funcionalidade por usuários, a fim de captar suas percepções. Portanto, o MVP é uma prática para validação por um cliente real com o menor investimento possível, a fim de avaliar a funcionalidade do produto antes de realizar grandes aportes de recursos e prosseguir com o escalonamento da tecnologia.

O MVP é essencial para levantar as informações a respeito da opinião de um cliente real e entender suas exigências, além de conhecer sua percepção a respeito do funcionamento do produto em desenvolvimento. Isso minimiza gastos desnecessários de tempo e dinheiro, além de diminuir o risco de obtenção de um produto ou processo distante das realidades comerciais. ${ }^{12,13}$

Com alguma frequência, após a realização do primeiro MVP, uma nova fase de desenvolvimento é iniciada, com o intuito de realizar as modificações necessárias, a fim de melhor atender o cliente. Portanto, trata-se de um processo interativo, com grande relevância para mapear os fornecedores de insumos, estabelecer contato e, de preferência, testar suas matérias-primas comerciais para a fabricação dos produtos e realização de testes, com intuito de tornar todo o processo mais próximo da realidade industrial.

De modo geral, toda essa interação com o mercado durante o MVP permite que novas possibilidades estratégicas sejam desenvolvidas, como o codesenvolvimento e a definição do modelo de negócio, fatores críticos para chegada do produto ao mercado.

Espera-se, portanto, que ao fim dessa etapa, tenha sido preparado um produto em quantidades maiores quando comparado à fase anterior, produzido a partir de insumos comerciais e testado com potenciais clientes.

As perguntas a serem respondidas ao final dessa etapa, para análise do amadurecimento da tecnologia para o escalonamento são mostradas no Quadro 3:

De forma a ilustrar melhor a Etapa 2, descrevemos abaixo (c.f. Quadro 4) um estudo de caso com o escalonamento em laboratório de um material para adsorção de fosfato de efluentes industriais.

\section{Etapa 3: desenvolvimento com foco no processo ainda em laboratório}

Objetivo: desenvolver o processo ainda em laboratório com simulação de operações unitárias típicas da indústria.

Escala: aproximadamente de dezenas de gramas até quilograma.

A fase de desenvolvimento do processo em laboratório é descrita aqui como uma fase "pré-piloto". Enquanto a etapa anterior
Quadro 3. Perguntas fundamentais a serem respondidas na Etapa 2

1. A produção do produto foi realizada a partir da aplicação de insumos e/ ou matérias-primas comerciais/industriais? Foram identificados os seus respectivos fornecedores?

2. O produto foi testado em laboratório e apresentou bom desempenho frente as funcionalidades que se propõe?

3. Foi realizada uma análise de mercado de modo a compreender quais são os clientes, quantos eles são e de fato do que precisam?

4. O produto foi testado junto a tais clientes (MVP) e apresentou bons resultados de desempenho?

5. O desempenho do produto produzido foi comparado com o desempenho de outros produtos concorrentes, disponíveis comercialmente? Qual apresentou melhor desempenho?

6. Os concorrentes do produto em desenvolvimento, bem como suas vantagens competitivas foram mapeados?

7. Diante das informações levantadas, foram definidas as estratégias a serem adotadas para a proteção do conhecimento gerado durante o desenvolvimento do produto?

Quadro 4. Caso de estudo - Adsorventes de fosfato

Durante cerca de dois anos, um material sintético foi desenvolvido em laboratório para a adsorção de fosfato. Foram obtidos mais de oito tipos diferentes de materiais com reagentes de laboratório, combinados de diversas maneiras e tratados a quatro temperaturas diferentes. O resultado foi um número enorme de experimentos, que permitiram decidir qual seria a melhor composição e as melhores condições de preparo dos materiais (tentativa de resposta à pergunta 2). A partir daí, decidiu-se fazer um teste real do material em uma indústria que demonstrou interesse pela tecnologia (tentativa de resposta às perguntas 3 e 4). Para isso, foi necessário preparar uma quantidade maior (aproximadamente $500 \mathrm{~g}$ ) de material. Os problemas iniciais que foram identificados estavam relacionados às dificuldades de obtenção dos insumos comerciais e a reprodução dos testes em laboratório (tentativa de resposta à pergunta 1). Foram necessárias algumas modificações nas condições de reação com os novos insumos. Além disso, a preparação de maiores quantidades também demandou alteração no processo, por exemplo na mistura/trituração e ao tratamento térmico dos materiais (tentativa de resposta à pergunta 5). Foi necessário encontrar um moinho para triturar/misturar os diferentes componentes e um forno mufla para calcinar maiores quantidades do material. Depois disso, foi necessário desenvolver recipientes plásticos especiais com o material adsorvente, pois até naquele momento o design do produto não havia sido pensado. Paralelamente, foram mapeados possíveis concorrentes da tecnologia com auxílio de busca de patentes e identificação de outras tecnologias semelhantes já protegidas. Essa busca facilitou o entendimento dos diferenciais tecnológicos do material desenvolvido em relação aos outros encontrados e, a partir disso iniciou-se a redação da patente para proteger o conhecimento gerado (tentativa de resposta às perguntas 6 e 7).

estava vinculada com a validação do produto em escala laboratorial aumentada, essa parte pretende validar as etapas do processo pensando na escala industrial. A ideia aqui é usar em escala de laboratório operações unitárias que são normalmente utilizadas na indústria e verificar se a eficiência do processo se mantém. Faixas de trabalho de até $1 \mathrm{~kg}$ ou litro são comuns nessa fase.

Nessa etapa pode-se identificar melhor potenciais riscos de operação, tais como inflamabilidade/explosão, toxicidade, formação de resíduos/rejeitos, etc.

Segundo Wood-Black, ${ }^{14}$ pode-se dizer que antes da definição do processo de modo a simular as operações unitárias aplicadas na indústria, existem obstáculos ainda não conhecidos que podem inviabilizar uma solução conceitual, por ocultar informações a respeito da real viabilidade econômica da tecnologia em desenvolvimento. $\mathrm{O}$ autor ainda afirma que tais obstáculos podem se tornar aparentes à medida que o processo se move da escala da 
bancada a escalas superiores, onde os testes serão executados com maiores quantidades de matérias-primas e insumos disponíveis comercialmente. Embora não seja possível prever os efeitos diretos associados ao escalonamento apenas com os resultados da escala de laboratório, os testes realizados na fase "pré-piloto" fornecem uma visão intermediária do processo. Ainda nessa fase, já se deve começar a pensar nos materiais dos reatores e itens presentes em cada uma das operações unitárias. Embora uma reação em escala de bancada possa ser conduzida em um recipiente de vidro, por exemplo, dependendo da quantidade de matéria-prima empregada no processo tal recipiente passa a ser inviável. É importante ressaltar que as alterações nos requisitos da metalurgia ou dos recipientes demandadas para o processo industrial podem requerer elevados investimentos e comprometer o aumento de escala e a viabilidade econômica final do projeto global.

\section{Operações unitárias}

Operações unitárias são as etapas básicas de um processo, como filtração, destilação, adsorção, moagem, secagem, etc. O sucesso no aumento da escala encontra-se relacionado à identificação das condições adequadas de todas as etapas envolvidas no processo produtivo, sendo essencial avaliar cada umas das operações unitárias empregadas. A diferenciação entre etapas de maior influência na qualidade do produto (como as que envolvem reações químicas) e de menor influência (como etapas físicas de centrifugação, filtração, etc.) são relevantes na identificação dos pontos mais sensíveis associados ao processo. Essa diferenciação é dependente não apenas da natureza das operações unitárias, mas principalmente das particularidades de cada processo. Por exemplo, uma operação de secagem pode apresentar pouca relevância para a qualidade estrutural de produtos minerais, contudo, pode representar alto impacto nas características de alguns produtos alimentícios liofilizados. ${ }^{15-18}$

As operações unitárias sem impacto significativo nas características dos produtos não requerem um desenvolvimento com o mesmo nível de detalhamento das demais, mas também não podem ser esquecidas, de modo a representarem gargalos expressivos de eficiência operacional. Por exemplo, o uso de uma centrífuga laboratorial de tubos geralmente é inviável para o aumento de escala, sendo necessária sua substituição por uma centrífuga de operação contínua ou semicontínua em processos de maiores escalas.

Ainda, existem questões mecânicas que devem ser abordadas, como, por exemplo, se o processo exigir a operação de mistura ou agitação, deve-se refletir sobre a melhor forma de sua execução em maior escala, verificar a necessidade da adição de uma nova etapa ao processo, bem como uma maneira de avaliar a qualidade daquela mistura. Ou caso essa qualidade não seja alcançada, é necessário avaliar quais são os impactos envolvidos no insucesso dessa atividade frente ao processo estabelecido para a produção da tecnologia em desenvolvimento.

\section{Variáveis de processo}

Segundo Thiry et al.,${ }^{19}$ nessa fase deve-se ter claro não apenas as matérias-primas, insumos, formulações e operações unitárias a serem aplicadas, mas também faixas de limites em cada uma das etapas do processo, de modo a garantir que o produto final atenda as expectativas estabelecidas. A fim de definir tais critérios que possibilitem avaliar a qualidade da homogeneização de uma mistura, ou sua taxa de dissolução, é importante definir parâmetros, como por exemplo uma faixa de tempo combinada a uma rotação a ser aplicada em dada operação unitária. Um exemplo prático foi o trabalho realizado por Thirry et al. ${ }^{19}$ a respeito dos parâmetros associados a aplicação da técnica de extrusão a quente no escalonamento de fármacos na indústria farmacêutica. Ao final do trabalho, foi possível comprovar a influência direta dos parâmetros temperatura, alimentação, do design e velocidade do parafuso contido na extrusora, nas características e qualidade dos produtos.

Alterações nas características do produto durante o escalonamento são comuns, que podem requerer tanto ajustes no processo, quanto um maior nível de controle para as variáveis determinantes. Segundo Tulcidas et al. ${ }^{20}$ os experimentos realizados em vidrarias de laboratório proporcionam uma área de superfície significativa para a transferência de calor e aproximam-se bem das condições de "misturas perfeitas" frente à transferência de massa. À medida que a escala aumenta, a relação entre a área superficial e o volume diminui e os gradientes de temperatura e / ou concentração tornam-se mais significativos se afastando das condições da "mistura perfeita". Portanto, ajustes de parâmetros podem ser necessários devido a diferenças de transferência de calor. Alterações também podem ser necessárias para propiciar o mesmo nível de homogeneização quando se trabalha em diferentes volumes e quantidades, como ajustes na potência ou no tempo de agitação de uma mistura.

A otimização dos parâmetros operacionais na execução de um processo é essencial para se estabelecer um aumento de escala com maior eficiência e qualidade. As variáveis com maior impacto na qualidade do produto e o seu grau de influência constituem pontos críticos de controle, portanto, sua identificação favorece de modo direto o processo de aumento da escala. Por exemplo, a redução do consumo de insumos líquidos pode propiciar uma infraestrutura mais enxuta do processo, além de menores custos variáveis e, possivelmente, um menor impacto ambiental devido à minimização da geração de resíduos. Ainda, a redução do volume requerido para o processo representa uma grande vantagem de eficiência operacional e maior facilidade no aumento da escala, pois possibilita expandir a capacidade produtiva em menores unidades de produção. Além disso, o aumento de rendimento e a otimização do tempo gasto no processo também contribuem para uma maior eficiência operacional e uma menor necessidade de expansão da infraestrutura física demandada para o aumento da escala. ${ }^{14}$

O objetivo desta fase pré-piloto é investigar a possibilidade de processos mais eficientes e otimizados, de modo a favorecer o aumento da escala e garantir a manutenção da qualidade do produto potenciando o emprego dos recursos. No entanto, nessa fase, não é necessário que haja um ajuste fino das variáveis de processo, apenas a definição das variáveis críticas de processo, bem como de suas faixas de valores. A realização de testes muito prolongados e o estabelecimento preciso das condições ótimas para cada variável não são recomendáveis nesse momento, pois esse trabalho exige um maior tempo de desenvolvimento e os valores definidos podem ser alterados durante a continuidade do aumento de escala. ${ }^{14}$

\section{Controle de qualidade}

À medida que o processo de escalonamento tem sua escala aumentada e é demandada a validação da aplicação da tecnologia em desenvolvimento, torna-se crescente a exigência do controle de qualidade por meio da definição de parâmetros a serem alcançados pela tecnologia. Possíveis desvios dos resultados frente aos processos executados em menores escalas devem ser avaliados de forma embasada, a fim de garantir a adequação do produto a seu padrão de identidade e qualidade. Além disso, a produção em escala aumentada pode requerer novos tipos de testes e caracterizações, como avaliações específicas para protótipos e peças de maior dimensão, a fim de comprovar sua viabilidade. ${ }^{21}$ A caracterização deve ser estruturada de modo a externar as propriedades da tecnologia, e avaliar se as faixas pré-determinadas para o padrão de identidade e qualidade da tecnologia foram mantidos. Além disso, o controle de qualidade deve ser sistemático e com enfoque nos benefícios para os usuários, 
os quais devem ser aferidos ao final de cada uma das fases durante todo o processo de aumento da escala. ${ }^{22}$

\section{Prova de Conceito 3 (POC 3) - Validação do processo}

Objetivos da POC 3: testar um processo com operações unitárias normalmente utilizadas nas indústrias para obter um produto para avaliação de possíveis clientes.

Nessa etapa, deve-se comprovar que o produto pode ser preparado por meio de um processo compatível com os princípios da indústria, com preservação de suas funcionalidades e benefícios de interesse do mercado. Essa POC3 de processo é extremamente importante porque é etapa anterior à da planta piloto, a qual está relacionada com uma pequena escala de base industrial, que envolve uma mudança expressiva no nível de complexidade. O desenvolvimento de uma planta piloto requer consideráveis investimentos financeiros, infraestrutura física ampliada, projetos de engenharia, aumento no tempo de dedicação e maiores cuidados com a segurança. Portanto, o estabelecimento bem estruturado da escala pré-piloto é de alta importância para evitar erros expressivos na posterior produção piloto, e ainda favorecer a captação de investimentos.

Uma análise da viabilidade econômica do processo também precisa ser realizada para justificar a etapa seguinte de produção piloto.

A POC 3 de processo nessa etapa deve comprovar que a escala pré-piloto, por meio de um processo viável economicamente, é compatível com operações típicas da indústria. Sua execução precisa garantir a manutenção das características do produto observadas anteriormente, preferencialmente levando em conta os aspectos levantados junto a validação feita com os clientes ou usuários visados para o produto. Portanto, a POC de processo é baseada na comprovação técnica-econômica de escala ampliada, com compatibilidade aos princípios de processamento industrial e manutenção das características do produto. Esses são os principais resultados que se espera alcançar na etapa pré-piloto para viabilização da posterior planta piloto efetiva. Sendo assim, as perguntas fundamentais a serem pensadas antes de se passar para a próxima etapa podem ser conferidas no Quadro 5:

Quadro 5. Perguntas fundamentais a serem respondidas Etapa 3

1. Todas as etapas de processo são compatíveis com operações típicas da indústria?

2. Com essas operações o processo ainda apresenta eficiência adequada? Algum aspecto crítico de transferência de massa e energia?

3. Nenhuma restrição crítica foi identificada para maiores aumentos de escala do processo?

4. As características do produto são mantidas?

5. Há confirmação de interesse dos possíveis clientes ou usuários em relação aos benefícios gerados pelo produto?

De forma a ilustrar melhor a Etapa 3, descrevemos abaixo (c.f. Quadro 6) um estudo de caso com estudos em escala pré-piloto.

\section{Etapa 4: desenvolvimento da planta piloto}

A construção e operação de uma planta piloto pode envolver uma enorme complexidade. Nesse artigo apresentaremos apenas uma ideia geral da Etapa 4 e como Parte 2 desse artigo publicaremos os detalhes desse processo.

Objetivo: executar o processo em escala mínima que represente a operação industrial e que forneça quantidades de produto suficiente para testes reais com potenciais clientes.
Quadro 6. Caso de estudo - Reaproveitamento de rejeito orgânico

No contexto de uma dissertação de mestrado, foi estudado, em escala de laboratório, um processo de transformação de um rejeito orgânico em um novo produto. Uma das etapas que feita em escala de bancada era uma filtração a vácuo em um funil de Büchner. Essa etapa era crítica e fazia com que o processo fosse extremamente demorado. Já era sabido que para aumentar a escala teria que ser feito com que esse processo de separação ocorresse utilizando algum outro equipamento/operação unitária industrial (tentativa de resposta à pergunta 1). Foram discutidas algumas possibilidades industriais: inicialmente centrífuga e filtro prensa, porém, esse tipo de equipamento não estava disponível no laboratório. Para testar se a separação desse produto do meio aquoso funcionaria via centrifugação ou filtro prensa, foi preparado 1 litro de amostra e essa amostra enviada para empresas que vendiam esse tipo de equipamento. Depois de algumas semanas, várias respostas de eficiências que foram extremamente importantes para decidir como o processo poderia acontecer em escala industrial foram obtidas (tentativa de resposta às perguntas 2 - 4). Nesse momento a pergunta 5 ainda não havia sido respondida.

Escala: aproximadamente de alguns quilogramas até toneladas ou $\mathrm{m}^{3}$.

A planta piloto é um conjunto de sistemas para executar o processo em condições suficientemente próximas às encontradas em uma planta industrial. Talvez um bom direcionador sobre a escala nessa etapa para minimizar o investimento e o trabalho seja: qual a menor escala possível para obter parâmetros relevantes para o projeto industrial? Qual a menor escala possível para obter produto em quantidade suficiente para um teste real e robusto com potenciais clientes? Construir e operar uma planta piloto é um processo normalmente complexo, longo e caro, sendo, portanto, fundamental otimizar esse trabalho. Para a construção de uma planta piloto é necessário um galpão com infraestrutura elétrica e hidráulica, com questões de segurança para abrigar todo o maquinário. $\mathrm{O}$ estoque de matéria-prima, bem como do produto, também deve ser levado em consideração no dimensionamento do galpão a ser utilizado. A periculosidade do armazenamento dos insumos e produtos manufaturados deve ser muito bem avaliada antes do início das operações. Os rejeitos gerados durante o processamento dos insumos, sua recuperação e descarte devem ser feitos de forma controlada e autorizada por órgãos de controle de manipulação de produtos químicos e de licenciamento ambiental. A escala de produção pode variar entre alguns quilogramas ou litros e até algumas centenas de $\mathrm{kg} /$ litros, devendo ser o volume médio de insumos e produtos químicos considerados no dimensionamento do espaço necessário para a operação da planta.

A planta piloto simula as condições reais de operação em uma escala reduzida, quando comparada com a planta industrial. A montagem de uma planta piloto envolve a busca por reatores que normalmente não estão disponíveis comercialmente e precisam ser encomendados em empresas especializadas. A montagem da planta piloto auxilia os pesquisadores a enxergarem os pontos críticos do processo e como as operações unitárias serão executadas em escala maior. Os custos do processo da produção de um produto são mais bem dimensionados quando os dados obtidos por um processamento em uma planta piloto são utilizados.

Durante as operações de uma planta piloto torna-se possível projetar melhor a mão de obra e os custos envolvidos como eletricidade, água, espaço físico, etc., de modo a gerar uma estimativa mais próxima aos custos reais de uma operação industrial. Outro ponto importante são os gastos necessários para obtenção do produto. Tais gastos encontram-se relacionados a compra de insumos em maiores quantidades, o que reduz significativamente seu custo de obtenção, mas também, normalmente, reduz sua pureza. O controle da qualidade da matéria prima é fator fundamental, está diretamente relacionado 
a qualidade dos produtos, e deverá ser levado em conta durante a operacionalização de obtenção do produto final.

Além dos custos relacionados à produção do produto, outros custos também devem ser levados em consideração, sendo as definições de CAPEX e OPEX também importantes. CAPEX é uma sigla em inglês que significa capital expenditure, referente às despesas de capital, portanto representa o custo para montar uma unidade industrial (equipamentos, instalações, etc.). OPEX, por sua vez, é uma sigla em inglês para operational expenditure, referente às despesas operacionais, e representa quanto custará para operar a planta de produção (gastos com água, energia, mão de obra, serviços terceirizados, etc.). Essas informações são geralmente necessárias para contatos com potenciais investidores, como por exemplo, fundos de investimento, bancos de financiamento tecnológico, dentre outros.

\section{Etapas de construção de uma planta piloto (resumo)}

1 - Fase de preparo

a) Projeto Conceitual

b) Projeto Básico

c) Projeto Executivo

d) Equipe

2 - Construção e operação

a) Montagem de Equipamentos

b) Planejamento dos testes com potenciais clientes

\section{Prova de Conceito 4 - Vendas}

O próximo passo é captar investimentos para o estabelecimento da indústria, em conjunto a profissionais com experiência na área, ou licenciar a tecnologia para alguma empresa ou grupo interessado. Esse momento representa a transição final para que a inovação seja de fato alcançada, com introdução da tecnologia na indústria e na sociedade.

\section{Escalonamento de tecnologias e o "Vale da Morte"}

Ao analisar-se as etapas de escalonamento de uma tecnologia, dentro de um contexto de inovação, deve-se ter em mente o mercado como objetivo maior do processo. Esse caminho, normalmente, é longo, turbulento e durante seu percurso se encontra o "vale da morte", conforme apresenta a Figura 2. Trata-se de uma região de extrema incerteza e riscos. Para aqueles que não desejam encarar seus desafios, o caminho mais tradicional e de menor energia é o de manter engavetados os projetos, sejam por meios de artigos que terão como finalidade a publicação, ou mesmo patentes acadêmicas, que facilmente poderão ser confundidas com publicações científicas.

O vale da morte é um estágio crítico, no qual a captação de
Quadro 7. Perguntas prévias à construção da planta piloto

1. A capacidade produtiva almejada foi implementada com sucesso e há uma base de referência para maiores aumentos de escala?

2. A infraestrutura foi completamente estabelecida e mostrou-se adequada para a planta piloto?

3. Os parâmetros de processo foram cuidadosamente definidos e há seu controle comprovado por múltiplas medidas com elevado rigor estatístico?

4. A logística de processo foi mapeada e definida de acordo com as melhores práticas de operação industrial?

5. O layout e a área requerida foram identificados de acordo com a capacidade produtiva?

6. Os requisitos ambientais e de segurança foram mapeados e são rigorosamente seguidos na planta piloto?

7. Os custos foram identificados e registrados em planilhas financeiras?

8. A iniciativa comercial resultou em interesse de compra pelo mercado?

recursos é extremamente importante. Nessa Figura 2 percebe-se que no início do desenvolvimento tecnológico (Fase 1), a maior parte dos recursos financeiros são públicos, visto que muitas vezes as agências de fomento governamentais estão organizadas para investir em pesquisa em escala de laboratório nas ICTs. À medida que a maturidade tecnológica do produto em desenvolvimento avança (Fase 3), essa fonte de recursos se torna cada vez mais escassa, de modo que, em um determinado momento, os investimentos devem passar a ser do setor privado. Entretanto, o setor privado avalia o risco com enorme cautela e busca investir em tecnologias mais estruturadas e em estágios mais avançados, mais próximas de se tornarem produtos ou processos que possam ser utilizados e vendidos.

Além do dilema sobre as fontes de financiamento, é na passagem pelo "Vale da Morte" que se espera uma interação entre os pesquisadores acadêmicos, governo, a indústria instalada e consumidores finais. ${ }^{23}$ Todos esses ambientes possuem linguagens, prioridades, ciclos de tempo e indicadores de sucesso muito distintos uns dos outros. É importante ressaltar que as quatro fases de escalonamento aqui descritas se encontram exatamente dentro desse "vale da morte" (c.f. Figura 2).

\section{CONSIDERAÇÕES FINAIS}

O escalonamento é uma etapa fundamental quando se pretende levar uma tecnologia das bancadas de laboratórios de pesquisa das Universidades para a indústria, mercado e sociedade. O escalonamento

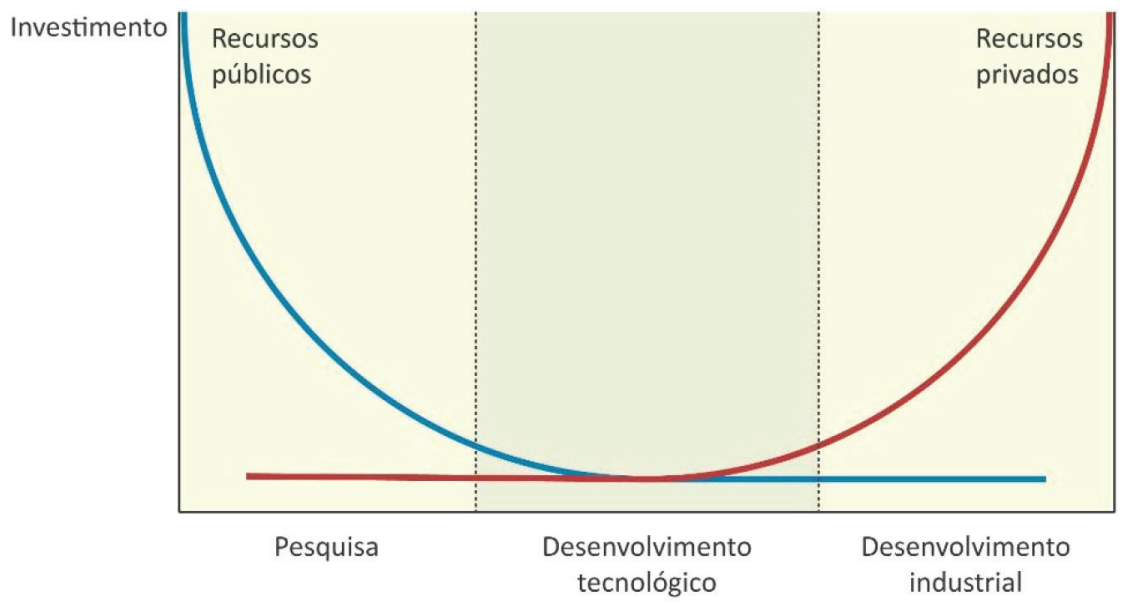

Figura 2. Relação de investimentos públicos VS investimentos privados para cada etapa do desenvolvimento de uma tecnologia 


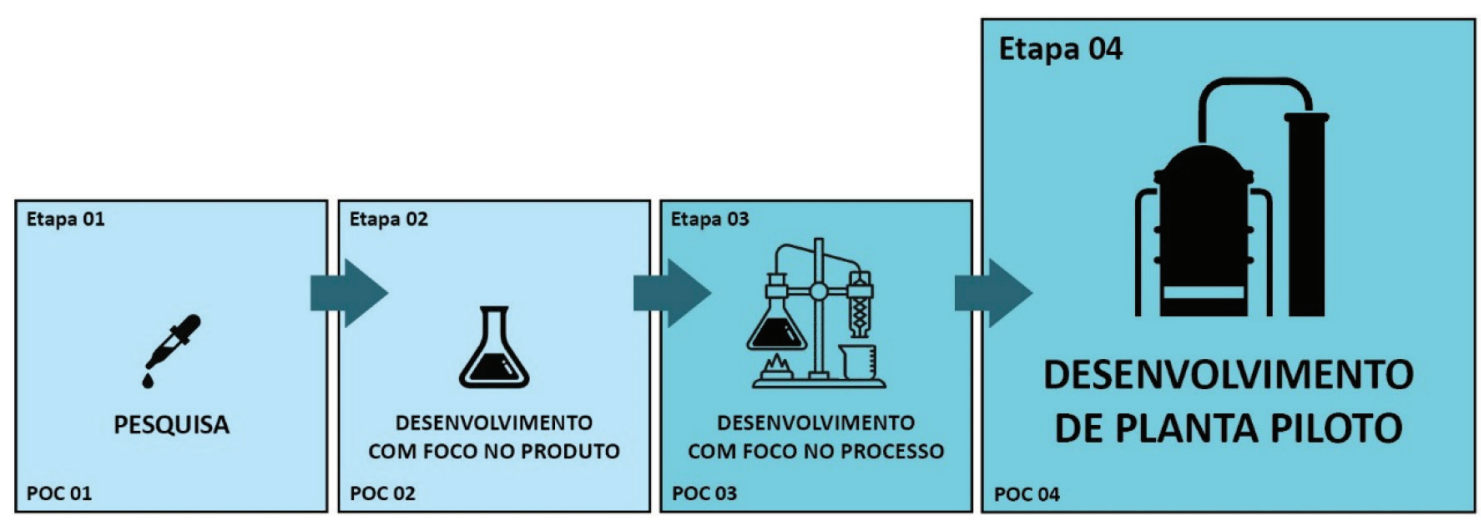

Figura 3. As quatro etapas fundamentais do processo de escalonamento de tecnologias, com destaque para a quarta e mais complexa etapa de desenvolvimento de uma tecnologia - a planta piloto

se faz para a realização de provas de conceito, i.e. verificar se o produto tem o desempenho aceitável, se é obtido em conformidade e se o processo funciona. Atualmente, essa etapa de escalonamento e provas de conceito em Hard Science, é sem qualquer dúvida, um dos maiores gargalos no processo de inovação. Não é exagero dizer que uma das principais razões da maior parte das patentes depositadas, relacionadas às Hard Sciences, nas Universidades, não chegar até o mercado está direta ou indiretamente relacionada às dificuldades na etapa de escalonamento e obtenção de provas de conceito. Neste trabalho é apresentada uma reflexão que considera aspectos de escalonamento desde a fase inicial de pesquisa nos laboratórios. Essa metodologia é dividida em Etapa 1 que envolve a pesquisa básica, Etapa 2 com foco no desenvolvimento de produto e Etapa 3 com foco no desenvolvimento de processo, todas ainda na escala de laboratório. O aspecto mais importante dessa compilação de ideias e reflexões é que muitas questões críticas podem ser respondidas ainda na fase de laboratório. Dessa forma, minimiza-se os riscos da Etapa 4, que é um processo bastante complexo, longo e caro de construção e operação da planta piloto. Este trabalho detalhou as Etapas 1, 2 e 3. A Etapa 4 de construção e operação da planta piloto será apresentada em um próximo trabalho (c.f. Figura 3).

\section{AGRADECIMENTOS}

Os autores gostariam de agradecer ao INCT-MIDAS pelo apoio e fornecimento de fontes de casos de estudo, à FAPEMIG pelo apoio incondicional às iniciativas de inovação e aos colegas que cuidadosamente leram nossos rascunhos e manuscritos e colaboraram com frutíferas discussões e palpites. Agradecem também ao Thiago Veloso pelo apoio no desenvolvimento das figuras deste trabalho.

\section{REFERÊNCIAS}

1. Boer, H.; During, W. E.; Int. J. Technol. Manage. 2001, 22, 14.

2. http://anpei.org.br/download/Mapa_SBI_Comite_ANPEI_2014_v2.pdf, acessada em outubro 2020.

3. Andrade, L. P. C. d. S.; Silva, R. C. d.; Mascarenhas, L. A. B.; Gomes, J. d. O.; Marinho, F. d. S.; Procedia CIRP 2016, 41, 177.

4. Araújo, M. H.; Lago, R. M.; Oliveira, L. C. A.; Cabral, P. R. M.; Cheng, L. C.; Filion, L. J.; Quim. Nova 2005, $28, \mathrm{~S} 18$.

5. Thorpe, M.; Ridgman, T.; Int. J. Innov. 2016, 13, 1750006.
6. https://www.usaid.gov/documents/1865/taking-innovations-scalemethods-applications-and-lessons, acessada em outubro 2020.

7. Magretta, J.; Szlak, C.; Entendendo Michael Porter: O guia essencial da competição e estratégia, Alta Books: Rio de Janeiro, 2018.

8. Porter, M., Estratégia Competitiva, Elsevier: Amsterdã, 2004.

9. Shane, S. A.; Academic Entrepreneurship: University Spinoffs and Wealth Creation, Edward Elgar: Cheltenham, 2004.

10. Speziali, M. G.; Guimarães, P. P. G.; Sinisterra, R. D.; Quim. Nova 2012, 35, 1700-1705.

11. Anônimo Ecossistemas de empreendedorismo inovadores e inspiradores; SEBRAE - ANPROTEC: Brasília, 2020.

12. Münch, J.; Fagerholm, F.; Johnson, P.; Pirttilahti, J.; Torkkel, J.; Järvinen, J. Em Lean Enterprise Software and Systems; Fitzgerald, B., Conboy, K., Power, K., Valerdi, R., Morgan, L., Stol, K. J., eds.; Springer: Berlin, Heidelberg, 2013, Vol. 167.

13. Moogk, D. R., Technol. Innov. Manage. 2012, $2,23$.

14. Wood-Black, F. Em Academia and Industrial Pilot Plant Operations and Safety, American Chemical Society: 2014, Vol. 1163, pp 37.

15. Foust, A. S.; Wenzel, L. A.; Clump, C. W., Maus, L.; Andersen, L. B.; Princípios das Operações Unitárias, LTC: Rio de Janeiro, 1982.

16. Terron, L. R.; Operações Unitárias Para Químicos, Farmacêuticos E Engenheiros: Fundamentos e Operações Unitárias do Escoamento de Fluidos, LTC: Rio de Janeiro, 2000.

17. Coulson, J. M.; Richardson, J. F.; Backhurst, J. R.; Harker, J. H., Coulson and Richardson's chemical engineering. Vol. 2, Particle Technology and Separation Processes, Butterworth-Heinemann: Oxford, 2002.

18. McCabe, W. L.; Smith, J. C.; Harriott, P.; Unit Operations of Chemical Engineering, McGraw-Hill Education: New York, 2005.

19. Thiry, J.; Krier, F.; Evrard, B., Int. J. Pharm. 2015, 479, 227.

20. Tulcidas, A.; Nascimento, S.; Santos, B.; Alvarez, C.; Pawlowski, S.; Rocha, F.; Sep. Purif. Technol. 2019, 213, 56.

21. Euzen, J. P.; Trambouze, P.; Wauquier, J. P.; Scale-up Methodology for Chemical Processes, Gulf Publishing Company: Houston,1993.

22. Ishii-Watabe, A.; Shibata, H.; Harazono, A.; Hyuga, M.; Kiyoshi, M.; Saitoh, S.; Iwura, T.; Torisu, T.; Goda, Y.; Uchiyama, S.; J. Pharm. Sci. 2017, 106, 3431.

23. Etzkowitz, H.; Zhou, C.; The Triple Helix: University-IndustryGovernment Innovation and Entrepreneurship, Taylor \& Francis: Oxfordshire, 2017. 